\title{
PENGARUH MARKET DAN LEARNING ORIENTATIONS TERHADAP RELATIONAL CAPABILITY DAN KINERJA USAHA UMKM DI KOTA MATARAM
}

\author{
Sulhaini ${ }^{1}$, Rusdan ${ }^{2}$, Sulaimiah ${ }^{3}$, Baiq Ismiwati ${ }^{4}$, Rahman Dayani ${ }^{5}$, \\ Rini Anggriani ${ }^{6}$
}

Magister Manajemen Universitas Mataram niniys@yahoo.co.uk

\begin{abstract}
The objective of the study is to examine the effect of organisational culture, i.e learning and market orientations toward relational capability and business performance of SMEs. The samples were purposively selected in the city of Mataram, they must have at least four employess. They were doorto-door approached during a four-week data collection period. The findings suggested that the orientations strengthen SMEs' relational capability and performance. Nonetheless, learning orientation does not guarantee better business performance unless the orientation is strongly implemented intofirms' relational capability. The study provides interesting contributions toward relationship marketing literature by giving evidences regarding the effects of the cultural orientations on SMEs' relational capability and perfromance. Founding of SMEs should emphasise on the development and implementation of learning and market orientations to improve their relational capability and performance.
\end{abstract}

Keywords: learning orientation, market orientation, relational capability, business performance

\begin{abstract}
ABSTRAK
Tujuan utama dari penelitian ini adalah untuk mnguji pengaruh dari budaya organisasi, yaitu orientasi belajar dan orientasi pasar terhadap kapabilitas relasional dan kinerja UMKM Sampel dipilih secara purposive di kota Mataram. Setiap sampel yang terpilih harus memiliki minimal empat orang karyawan. Mereka dihubungi secara langsung selama empat minggu periode pengumpulan data. Hasil penelitian menunjukkan bahwa kedua orientasi dapat memperkuat kapabilitas relasional dan kinerja UMKM. Akan tetapi, orientasi belajar tidak dapat menjamin kinerja usaha yang lebih baik, kecuali orientasi ini diimplementasikan secara kuat kedalam pengembangan kapabilitas relasional. Penelitian ini memberikan kontribusi penting bagi pengembangan literatur relationship marketing dengan memberi bukti empiris terkait pengaruh kedua orientasi budaya organisasi terhadap kapabilitas relasional dan kinerja usaha. Pembinaan UMKM perlu menekankan pada pengembangan dan implementasi orientasi belajar dan orientasi pasar untuk meningkatkan kapabilitas relasional dan kinerja mereka.
\end{abstract}

Katakunci: orientasi belajar, orientasi pasar, kapabilitas relasional dan kinerja usaha 


\section{PENDAHULUAN}

Teori relationship marketing telah menandai paradigma baru dalam ilmu manajemen pemasaran (Kucukancabas et al., 2009) yang memandang konsumen sebagai pihak yang secara aktif terlibat dalam pembentukan dan pengembangan hubungan bisnis. Kapabilitas relasional ditunjukkan oleh kualitas hubungan bisnis. Kapabilitas ini menuntut adanya budaya perusahaan (corporate culture) yang kondusif (Sulhaini, 2011; Iglesias et al. 2011). Akan tetapi, Hakala and Kohtamaki (2011) menyatakan bahwa masih sangat sedikit penelitian yang menggali pengaruh budaya organisasi dan pengaruhnya terhadap kemampuan relational perusahaan.Penelitian yang menggali relational capability masih sangat terfragmentasi (Smirnova et al., 2009). Sementara itu, market orientation(MO) dan learning orientation (LO)telah dipandang sebagai budaya organisasi yang dianggap berperan penting dalam menentukan kinerja usaha(Foley and Fahy, 2004, Wang and Wei, 2005; Gonzales-Benito et al., 2009). Dengan demikian, penelitian ini menguji pengaruh budaya organisasi yaitu: market oientation dan learning orientation terhadap relational capability dan kinerja usaha.Penelitian ini bertujuan untuk berkontribusi dalam pengembangan literatur relationship marketing dengan memberikan bukti empiris terkait pengaruh market orientationdan learning orientationterhadap kemampuan relational dan kinerja UMKM di Mataram. Penelitian ini diharapkan dapat memperkaya literatur relationship marketing dan bahan ajar manjemen pemasaran.

\section{TINJAUAN PUSTAKA DAN PERUMUSAN HIPOTESA}

Semakin dinamisnya lingkungan bisnis menuntut kualitas hubungan yang lebih tinggi dan didasari oleh budaya organisasi yang mantap dan kuat (Sulhaini, 2012). Budaya organisasi dibutuhkan untuk menguatkan hubungan dengan mitra guna mendorong inovasi dan sharing pengetahuan (Jarratt, 2004). Ini menyiratkan bahwa budaya organisasi menjadi penentu awal dari kemampuan relational suatu lembaga bisnis.

Kapabilitas relasional (Relational Capability/RC) merupakan kemampuan sebuah lembaga bisnis membangun dan mengelola organisasi dan orientasi budayanya yang berfokus pada mempertahankan pelangggan. Orientasi ini harus dimiliki oleh seluruh anggotanya (Day, 2003). Smirnova et al. (2009) kemudian menyebutkan bahwaRCmerupakan kemampuan sebuah organisasi bisnis dalam mengidentifikasi dan meraih peluangusaha, mengembangkan pengetahuandan kompetensi untuk membangun daya saing yang berkelanjutan dengan memanfaatkan hubungan bisnis yang dimilikinya. Sivadas dan Dwyer (2000) sebelumnya menunjukkan bahwa kemampuan ini ditentukan oleh saling percaya, komunikasi dan koordinasi antar organisasi bisnis. Sehingga RC yang kuat membuat perusahaan memiliki kemampuan kerjasama, komitmen dan kepercayaan yang lebih kuat (Rodriguez-Diaz dan Espino-Rodriguez, 2006). Sejalan dengan itu, Sulhaini (2012) menjelaskan pula bahwa RC terdiri dari tiga dimensi utama relationship marketing, yakni: kepercayaan, komitmen dan kepuasan. Sehingga pengukuran relational capability UMKM dalam penelitian ini menggunakan ketiga dimensi tersebut.

Dalam penelitian ini, budaya organisasi yang pertama adalah learning orientation (LO). Proses belajar tak dapat dipisahkan dari manajemen hubungan bisnis karena perusahaan dapat belajar tentang konsumen, pasar bahkan pesaingnya melalu interaksi yang kontinyu dalam hubungan bisnis (Gima, 2002) sehingga dapat dikatakan pula bahwa hubungan bisnis merupakan arena untuk belajar (Nykanen et al., 2009). Hal ini 


\section{$J M M$ UNRAM

mengindikasikan LO diperlukan dalam membangun hubungan bisnis di mana proses belajar berjalan yang pada akhirnya akan membawa pada kesuksesan.

$R C$ merupakan kemampuan perusahaan dalam berinteraksi dengan mitra untuk mengakselerasi akumulasi pengetahuannya melalui proses belajar didalamnya, dengan demikian LO memiliki pengaruh terhadap kemampuan tersebut (Jarratt, 2004). Hal ini sejalan dengan padangan dari Celuch et al (2002) yang mengaskan bahwa LO adalah faktor penentu dari RC. Dengan demikian dapat dikatakan bahwa, perusahaan yang memiliki LO yang tinggi akan memiliki kemampuan membangun kemitraan eksternal termasuk pelanggan yang lebih kuat. Perusahaan yang berorientasi pada learrning dapat menstimulasi upaya untuk menggali peluang dari hubungan bisnis sebagai bagian dari peningkatan kompetensi untuk meraih keunggulan bersaing.Jones et al. (2003) menyebutkan bahwa LO sebagai konsep yang dinamis sekaligus kompleks yang berfokus pada perubahan yang kontinyu dari sebuah perusahaan. LO merupakan fondasi dari upaya-upaya terintegrasi di dalam perusahaan maupun dengan pelanggannya. Perusahaan yang memiliki LO mampu mempertahankan hubungan kuat dengan konsumen sebagai antisipasi perubahan lingkungan bisnis yang tak diharapkan (Kropp et al., 2006).Di sini terlihat bahwa peranan hubungan bisnis tidak hanya memfasilitasi penjualan tapi juga belajar dan tak kalah pentingnya yaitu menangkap peluang sekaligus mengurangi resiko kegagalan karena dinamika pasar.

Pengaruh kuat antara LO terhadap RC telah diuji oleh beberapa peneliti sebelumnya. Santos-Vijande et al (2005) menemukan bahwa LO mempengaruhi tingkat kepercayaan dan komitmen terhadap konsumen dan keduanya merupakan dimensi dari RC. Begitupula Nykanen et al., (2009) menunjukkan bahwa kepercayaan didukung atau bahkan diciptakan melalui proses belajar dan keinginan untuk belajar tentang pelanggan dapat dipandang sebagai komitmen terhadap pelanggan. Hal ini menyiratkan lagi bahwa proses belajar mempengaruhi tingkat kepercayaan dan komitmen di dalam hubungan bisnis.Sejalan dengan itu, Panayides (2007) menyimpulkan bahwa LO berpengaruh terhadap RC.Perusahaan dengan budaya LO kuat akan memiliki kecenderungan untuk belajar secara berkesinambungan tentang pelangganmelalui upaya-upaya kuat dalam komunikasi, empaty, dan kepercayaan dengan pelanggan. Budaya ini menjadi kontributor potensial ke pengembangan hubungan bisnis karena mengandung nilai-nilai yang dapat mempengaruhi perilaku dan orientasi perusahaan dan anggotanyaterhadap formasi dan penguatan hubungan bisnis. Ini semua mengindikasikan bahwa LO berpengaruh secara langsung terhadap RC, dengan demikian hipotesa pertama yang diajukan sebagai berikut:

\section{H1: Semakin kuat Learning orientationsemakin kuat pularelational capability}

Investigasi terhadap penomena market orientation seharusnya dikaitkan dengan RC. Sanzo et al. (2003) menjelaskan bahwa MO menuntut staf yang terlibat dan berinteraksi dalam hubungan bisnis dengan pelanggan akan memiliki pemahaman yang kuat dengan masing-masing pelanggan dan pesaing. Mereka menjelaskan pula bahwa MO tidak berarti orientasi terhadap pasar secara umum namun orientasi terhadap individual pelanggan. Hal ini tentunya sejalan dengan tujuan utama dari strategi relationship marketing, yaitu mempertahankan pelanggan yang profitable bukan pada pengumpulan pelanggan sebanyak-banyaknya. Dengan demikian, MO harus terimplementasikan secara mantap dalam aktifitas mengembangkan RC. MO sebagai budaya mengarahkan orientasi perusahaaan terhadap kepuasan pelanggannya. Komunikasi yang terbuka dan saling percaya dengan pelanggan mengurangi tekanan atau konflik dapat menciptakan kepuasan sosial konsumen. Sehingga RC yang kuat dipandang dapat mempengaruhi kemampuan 


\section{$J M M$ UNRAM \\ JURNAL MAGISTER MANAJEMEN UNIVERSITAS MATARAM Maret 2018 \\ e- issn : 2548-3919}

perusahaan dalam meningkatkan kepuasan konsumen, karenna orientasi tersebut mempengaruhi komunikasi antara perusahaan dan meningkatkan kepercayaan di dalam hubungan bisnis (Sanzo et al, 2003).Ini menunjukkan MO mendorong penguatan hubungan dengan pelanggan.Smirnova dan Kushsh (2006) menemukan bahwa MO memiliki pengaruh positif terhadap RC.

Hubungan bisnis yang kuat menuntut RC yang kuat dan RC membutuhkan MO karena orientasi tersebut mempengaruhi kemampuan perusahaan mengembangkan hubungan bisnis (Smirnova et al., 2009).Dimensi MO yaitu customer orientation dapat dipandang sebagai penentu kemampuan perusahaan dalam memngelola hubungan karena perusahaan dapat fokus pada pemahaman kebutuhan pelanggan. Ini menunjukkan bahwa orientasi kepada pelanggan dapat dipandang sebagai komitmen kepada pelanggan yang juga dengan sendirinya harus dipandang sebagai komitmen dalam hubungan bisnis.Selanjutnya, Tan et al. (2009) meyakini perusahaan yang memiliki keinginan kuat untuk meningkatkan kinerja usahanya akan menekankan perhatiannya pada keterkaitan antara MO dengan RC. MO memacu perusahaan untuk mencari informasi tentang pelanggan dan pesaing serta membangun kemampuannya untuk mengelola hubungan bisnis dengan pelanggan. Sehingga MO berpengaruh positif terhadap RC. Dengan demikian, hipotesadua dapat dirumuskan sebagai berikut:

\section{H2: Semakin kuat market orientation semakin tinggi pula relational capability}

Hasil dari proses belajar yang dijalankan perusahaan yang memiliki LO yang kuat adalah pemahaman/pengetahuan penting yang akan membantu perusahaan untuk membangun strategi untuk meraih kinerja yang lebih baik (McGuiness and Morgan, 2006).Perusahaan seperti ini memiliki kemampuan inovasi yang lebih baik dan mampu mengikuti perkembangan tuntutan persaingan (Lin et al., 2008). Perusahaan ini akan memnunjukkan kemampuan belajar dengan cepat dan dinamis, mampu menganalisa arah perubahan atau trend pasar sehingga mampu membangun strategi bersaing yang tepat. Perusahaan berorientasi pada learningakan mengedepankan belajar dari dan bersama pelannggannya demi menjamin kesuksekan pemasaran (Matthing et al, 2004).Hal terpenting dari budaya belajar yang kuat adalah bahwa semua anggota organisasi/perusahaan untuk memiliki kebebasan untuk belajar agar dapat memuaskan keinginan pelanggan yang senantiasa dinamis. Dengan demikian budaya ini menstimulasi kreativitas dan kerjasama internal agar dapat menciptakan produk yang tepat bagi pelanggan.Uraian ini menunjukkan bahwa LO sebagai budaya organisasi yang dapat mengantarkan perusahaan pada kinerja usaha yang memuaskan. Pengaruh LO terhadap kinerja usaha telah didukung oleh penelitian Baker dan Sinkula (1999)dan Farrell (2000) yang menemukan pengaruh kuat LO terhadap kinerja usaha. Dengan demikian hipotesa di bawah ini dapat ajukan:

\section{H3. Semakin kuat learning orientation semakin baik pula kinerja usaha}

Di dalam lingkungan bisnis yang semakin dinamis, selera konsumen selalu mengalami perubahan dan perusahaan dituntut untuk selalu mengamati perubahan tersebut dan memastikan kemampuannya untuk menawarkan produk yang selalu sesuai dengan dinamika tersebut. Dalam kondisi seperti ini, MO merupakan orientasi yang yang dipandang mampu untuk menjamin kinerja usaha karena orientasi ini menekankan pada pencarian peluang pasar dan pengembangan strategi yang responsif untuk mencapai kinerja yang lebih baik (Gonzales-Benito et al., 2009). Demikian pula dengan Nasution dan Mavondo (2008) yang meyakini MO akan membawa perusahaan untuk mampu 


\section{$J M M$ UNRAM \\ JURNAL MAGISTER MANAJEMEN UNIVERSITAS MATARAM Maret 2018 \\ e- issn : 2548-3919}

menciptakan nilai yang lebih optimal dan dan mencapai kinerja yang lebih baik. Hal ini disebabkan adanya kecenderungan untuk berorientasi ke pada pelanggan mengantarkan perusahaan memahami pelanggan secara mendalam yang memungkinkannya mampu menciptakan nilai pelanggan yang optimal.

MO mengantarkan perusahaan untuk senantiasa melakukan pencarian peluang pasar dan pengembangan strategi yang responsif untuk mencapai kinerja yang lebih baik (Gonzales-Benito et al., 2009).Ini menuntut kemampuan perusahaan untuk mengumpulkan dan menyebarkan informasi ke pembuat keputusan di dalam perusahaan serta reaksi terhadap informasi agar dapat menciptakan nilai pelanggan yang paling superior dan lebih memuaskan dibanding pesaing (Sanzo et al., 2003). Dengan demikian MO mendorong aktifitas intelijen pemasaran dan akuisisi informasi pasar yang mengarah pada kebutuhan pelanggan sekarang maupun yang akan datang, diseminasi informasi dan respon organisasi secara luas (Kohli and Jaworski, 1990). Secara singkat, MO sebagai orientasi budaya, perusahaan akan mampu menyatukan seluruh upaya-upaya dalam proses penciptaan nilai pelanggan, diseminasi dan respons terhadap intelijen pasar untuk memperbesar peluang kesuksesan kegiatan pemasaran dan tentunya dapat meningkatkan kinerja usaha (Pentina dan Strutton, 2007). Oleh karena itu, hipotesa berikutnya adalah,

\section{H4. Semakin kuat marke orientation semakin baik kinerja usaha}

Hubungan bisnis yang kuat ditandai oleh adanya aktivitas dan sumber daya yang saling terkait antar pihak (perusahaan dengan pelanggannya) akan menghasilkan nilai yang lebih tinggi bagi masing-masing. Keterkaitan ini dapat berkembang tergantung pada intensitas interaksi dalam hubungan bisnis yang mengarah pada peningkatan kinerja usaha. Masing-masing pihak di dalam hubungan tersebut dapat menikmati berbagai keuntungan/manfaat seperti: penghematan biaya, keuntungan, berbagi resiko dan pengembangan kompetensi baru bagi perusahaan yang terlibat (Ngugi et al., 2010). Ini berarti bahwa sebuah hubungan bisnis untuk dapat berlanjut maka ke dua belah pihak harus dapat memberikan kontribusi bernilai bagi mitra sekaligus mendapatkan manfaat dan ini hanya dapat terwujud apabila hubungan tersebut menguntungkan dan menyenangkan yang semuanya ini bergatung pada RC yang kuat.Hubungan bisnis yang kuat merupakan hasil dari RC yang kuat di mana perusahaan dapat memperoleh ide-ide pengembangan produk baru yang membantunya lebih kompetitif dibanding pesaing. RC membantu perusahaan mengidentifikasi kebutuhan latent konsumen kemudian mengembangkan sistem internal organisasi perusahaan sebagai respon untuk mendukung pengembangan produk baru dari tahap awal hingga pemasarannya sehingga kesuksesan pengembangan produk baru dapat terjamin.

Broring dan Cloutier (2008) menegaskan RC menjadi penentu kinerja usaha di mana tantangan dalam meningkatkan kinerja usaha melalui pengembangan produk baru adalah membangun hubungan bisnis yang kuat dengan pelanggan yang tepat pada saat yang tepat pula. Sejalan dengan itu, Ngugi et al. (2010) menyiratkan bahwa di dalam hubungan bisnis yang kuat dapat memperbesar peluang peningkatan penjualan karena hubungan bisnisnya mendorong kecepatan inovasi yang berkelanjutan. Kerjasama yang ditandai oleh saling percaya dan komitmen kuat akan memperpendek waktu dan mengurangi resiko kegagalan dalam pemasaran produk dan meningkatkan daya saing perusahaan. Dengan kata lain, inovasi melalui kerjasama dengan pelanggan menjamin kesuksesan produk baru baik dalam proses pengembangan hingga pemasarannya. Secara sederhana dapat disimpulkan bahwa kinerja usaha bergantung pada RC. Secara singkat hipotesa terakhir dapat dirumuskan sebagai berikut: 


\section{H5. Semakin kuat relational capability semakin baik pula kinerja usaha}

Kerangka konseptual berikut merangkum dan mengilustrasikan semua hipotesa yang telah dikembangkan di atas.

Gambar 1. Kerangka konseptual

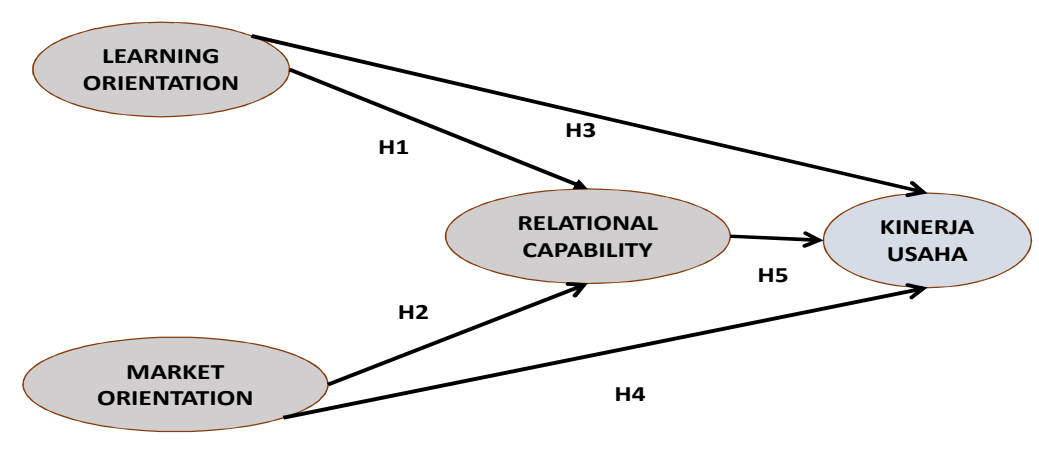

3. METODE

Populasi dalam penelitian ini adalah semua UMKM yang bergerak di bidang usaha makan/minumandan kerajinan yang berada di Kota Madya Mataram. Adapun jumlah sampel adalah 107UMKM, dimana pemilik/pengusaha dari masing-masing UMKM menjadi respondennya yang tentunya berjumlah 107orang. Jumlah ini sudah sesuai dengan penggunaan alat analisis data yaitu Structural Equation Modelling (SEM) yang mensyaratkan jumlah minimal sampel 100 (Ferdinand,2014).Teknik pengambilan sampel yang digunakan dalam penelitian ini adalah purposive sampling dari teknik sampling Non-Probability SamplingKriteria yang ditetapkan dalam penelitian ini adalah para pengusaha kerajinan yang memiliki minimal empat karyawan. Kriteria ini ditetapkan karena untuk mengukur market orientationdan learning orientationakan berkaitan dengan kerjasama di dalam perusahaan yang melibatkan beberapa orang dari berbagai fungsi/tugas yang berbeda. Karakteristik UMKM yang dijadikan sampel dapat dilihat pada Tabel 1.

Tabel 1. Deskripsi sampel

\begin{tabular}{|l|c|c|}
\hline \multicolumn{1}{|c|}{ Kepemilikan usaha } & Frekuensi & \% \\
\hline Milik sendiri & 88 & 82,2 \\
\hline Usaha Keluarga & 16 & 15,0 \\
\hline Usaha Patungan & 3 & 2,8 \\
\hline Jenis usaha & \multicolumn{2}{|c|}{} \\
\hline Kerajinan & 42 & 39,2 \\
\hline Pengolahan makanan/minuman & 54 & 50,5 \\
\hline Lainniya & 11 & 10,3 \\
\hline Umur responden & 23 & 21,5 \\
\hline $18-30$ & 30 & 28,0 \\
\hline $31-40$
\end{tabular}




\section{$J M M$ UNRAM \\ JURNAL MAGISTER MANAJEMEN UNIVERSITAS MATARAM Maret 2018 \\ e- issn : 2548-3919}

\begin{tabular}{|c|c|c|}
\hline $41-50$ & 37 & 34,6 \\
\hline$>51$ & 17 & 15,9 \\
\hline \multicolumn{3}{|c|}{ Jumlah karyawan (Orang) } \\
\hline $4-10$ & 64 & 59,8 \\
\hline $11-20$ & 29 & 27,1 \\
\hline $21-30$ & 14 & 13,1 \\
\hline$>31$ & 0 & 0 \\
\hline \multicolumn{3}{|c|}{ Umur perusahaan (Tahun) } \\
\hline$<5$ & 38 & 35,5 \\
\hline $6-10$ & 36 & 33,6 \\
\hline $11-20$ & 20 & 18,7 \\
\hline$>21$ & 13 & 12,1 \\
\hline \multicolumn{3}{|l|}{ Tingkat Pendidikan } \\
\hline Tidak pernah sekolah & 0 & 0 \\
\hline SD & 19 & 17,7 \\
\hline SMP & 37 & 34,6 \\
\hline SMA & 31 & 29,0 \\
\hline Diploma/S1 & 20 & 18,7 \\
\hline S2 & 0 & 0 \\
\hline \multicolumn{3}{|c|}{ Nilai penjualan (juta rupiah) } \\
\hline$<100$ & 44 & 41,1 \\
\hline $101-250$ & 25 & 23,4 \\
\hline $251-500$ & 17 & 15,9 \\
\hline $501-1$ milyar & 11 & 10,3 \\
\hline$>1$ milyar & 10 & 9,3 \\
\hline \multicolumn{3}{|l|}{ Tempat usaha } \\
\hline Ampenan & 24 & 22,5 \\
\hline Mataram & 65 & 60,7 \\
\hline Cakranegara & 18 & 16,8 \\
\hline
\end{tabular}

Dalam penelitian ini, $L O$ diukur dengan menggunakan indikator yang telah dikembangkan oleh Wang and Wei (2005). Orientasi ini dioperasionalkan sebagai tanggapan responden tentang bagaimana budaya belajar di dalam perusahaannya dengan tiga indikator, yaitu open mindedness, shared vission dan commitmen on learning. Sementara itu, $\mathrm{MO}$ dalam penelitian inidipandang sebagai budaya organisasi, sehingga definisi maupun pengukurannya menggunakan perspektif budaya organisasi Sehingga indikatornya adalah: Customer orientation, competitor orientation dan interfunctional coordination (Sanzo et al., 2003). Selanjutnya, relational capability dipandang sebagai sebuah konstruk multidemensional terdiri dari trust, commitment and satisfaction, indikator relational capability mengikuti penelitian dari Voss et al. (2006) dan Chung et al. (2011). Untuk pengukuran kinerja usaha menggunakan empat indikator dari riset (Hakala dan Kohtamaki (2011). Seluruh kontsruk dalam penelitian ini menggunakan seven-point Likerttype scales dengan pilihan sebagai berikut: sangat tidak setuju (1) hingga sangat setuju.(7).

Hasil uji instrumen dirangkum pada Tabel 2. Data pada tabel 2 menunjukkan bahwa standardized factor loading, Alpha Cronbach, composite reliability (CR) dan Average Variance Extracted (AVE), maka instrumen yang digunakan sudah valid (convergen validity) dan reliabel. Hal ini karena nilai factor loading semuanya di atas nilai ambang 
batas minimal (0.50) sedangkan alpha crobach dan composite reliability di atas 0.70 , begitu pula dengan nilai AVE di atas 0.50 (Hair et al., 2006). Selanjutnya untuk menguji discriminant validity, tim menggunakan perbandingan nilai akar AVE dengan nilai korelasi antar variabel. Tabel 3 menujukkan bahwa nilai akar AVE lebih tinggi dari korelasi antar variabel. Dengan demikian dapat disimpulkan bahwa instrumen valid dan reliabel.

Tabel 2. Hasil uji instrumen

\begin{tabular}{|c|c|c|c|c|}
\hline Variabel & $\begin{array}{c}\text { Standardised } \\
\text { Loading }\end{array}$ & a & CR & AVE \\
\hline Learning orientation & & ,951 & ,91 & 88 \\
\hline Commitment to Learning & ,78 & & & \\
\hline Shared Vision & ,92 & & & \\
\hline Open mindedness & ,94 & & & \\
\hline Market Orientation & &, 927 &, 93 & ,903 \\
\hline Consumer orientation & ,91 & & & \\
\hline Competitor orientation & 95 & & & \\
\hline Interfunctional coordination & ,85 & & & \\
\hline Relational Capability & & ,892 &, 85 & ,698 \\
\hline Credibility trust & 68 & & & \\
\hline Benevolent Trust &, 57 & & & \\
\hline Calculative Commitment & ,89 & & & \\
\hline Affective Commitment &, 77 & & & \\
\hline Economic satisfaction & ,74 & & & \\
\hline Social Satisfaction &, 54 & & & \\
\hline Business Performance & & .779 &, 79 & ,688 \\
\hline Kepuasan atas kinerja &, 53 & & & \\
\hline Keuntungan dibanding pesaing &, 56 & & & \\
\hline Pertumbuhan dibanding pesaing & 97 & & & \\
\hline $\begin{array}{l}\text { Mampu mempertahankan pelanggan } \\
\text { dibanding pesaing }\end{array}$ & ,69 & & & \\
\hline
\end{tabular}

Tabel 3. Discriminant validity

\begin{tabular}{|c|c|c|c|c|c|c|}
\hline & Mean & St Dev & $\mathrm{MO}$ & $\mathrm{LO}$ & $\mathrm{RC}$ & $\mathrm{BP}$ \\
\hline $\mathrm{MO}$ & 5,366 & 1,287 & 0,950 & & & \\
\hline LO & 4,891 & 1,713 & 0,000 & 0,938 & & \\
\hline $\mathrm{RC}$ & 5,456 & 0,794 & 0,232 & 0,318 & 0,836 & \\
\hline $\mathrm{BP}$ & 5,825 & 0,806 & 0,529 & 0,204 & 0,422 & 0,829 \\
\hline
\end{tabular}




\section{TMRNAL MAGISTER MANAJEMEN UNIVERSITAS MATARAM Maret 2018

\section{HASIL DAN PEMBAHASAN}

Pengujian model dilakukan dengan bantuan AMOS 22 adapun hasilnya dapat dilihat pada gambar dibawah ini

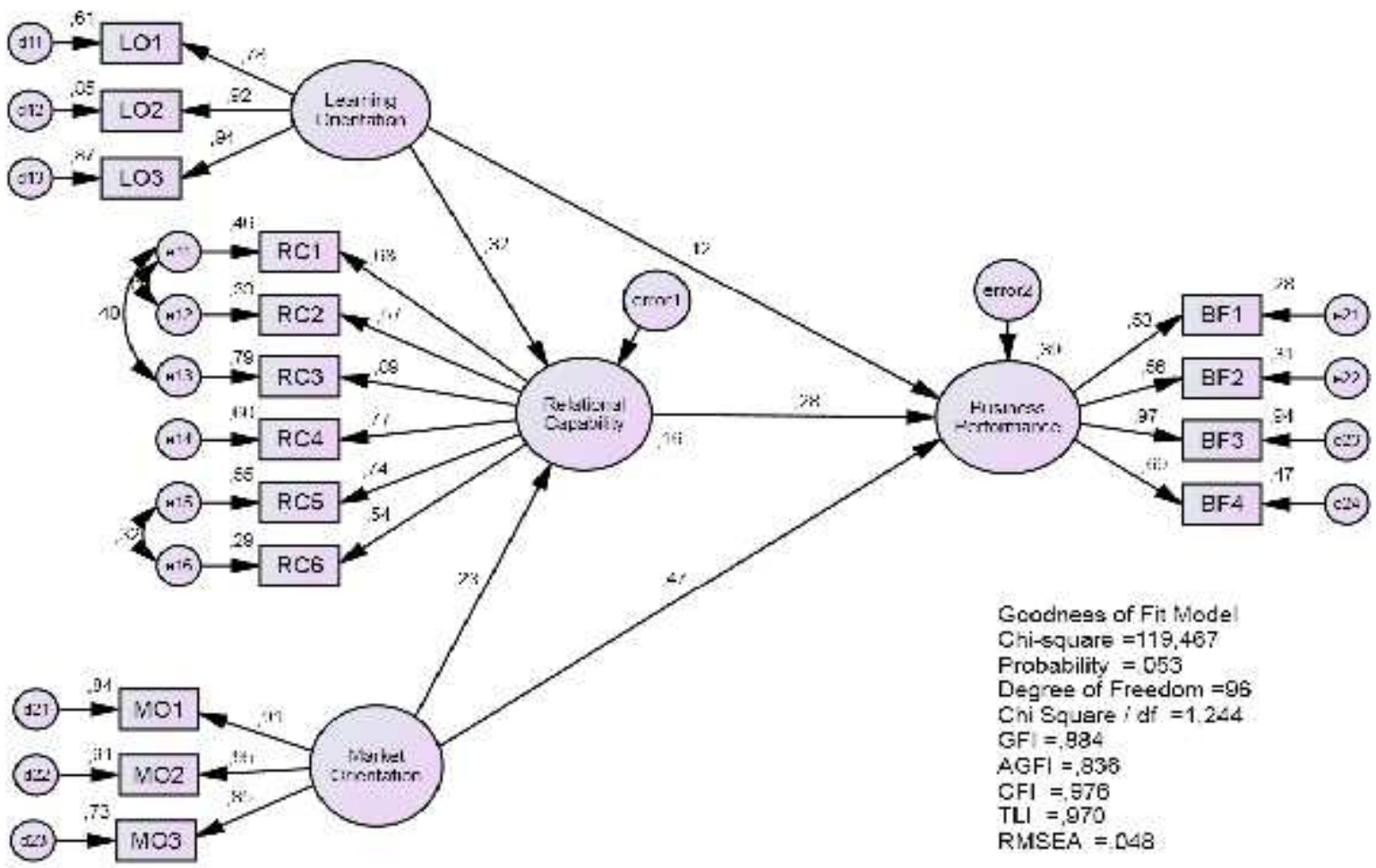

Bila dilihat hasil uji model di atas dapat disimpulkan bahwa model sudah fit. Hal ini didasarkan pada nilai CFI dan TLI di atas nilai 0.90, nilai RMSEA dibawah 0.08 serta nilai CMIN/DF di bawah 2. Berdasarkan hasil ini, maka langkah selanjutnya adalah menguji hipotesa penelitian sebagaimana diuraikan pada bagian berikut.

Uji hipotesa penelitian dilakukan dengan menggunakan AMOS 22 adapun hasilnya dapat dilihat pada tabel 4 di bawah ini. Tabel tersebut menunjukkan bahwa hanya hipotesa 3 yang sebagian terdukung (partly supported), sedangkan empat hipotesa lainnya terdukung oleh data dalam penelitian ini.

Tabel 4. Hasil uji hipotesa

\begin{tabular}{|c|l|r|r|r|}
\hline Hipotesa & \multicolumn{1}{|c|}{ Jalur } & Estimate & \multicolumn{1}{c|}{ P } & \multicolumn{1}{c|}{ Kesimpulan } \\
\hline H1 & LO $\rightarrow$ RC &, 117 &, 003 & Terdukung \\
\hline H2 & MO $\rightarrow$ RC &, 112 &, 022 & Terdukung \\
\hline H3 & $\begin{array}{l}\text { LO } \rightarrow \text { Kinerja } \\
\text { usaha/BF }\end{array}$ &, 042 &, 204 & Sebagian terdukung \\
\hline H4 & $\begin{array}{l}\text { MO } \rightarrow \text { Kinerja } \\
\text { usaha/BF }\end{array}$ &, 218 & $* * *$ & Terdukung \\
\hline H5 & $\begin{array}{l}\text { RC } \rightarrow \text { Kinerja } \\
\text { usaha/BF }\end{array}$ &, 269 &, 012 & terdukung \\
\hline
\end{tabular}




\section{$J M M$ UNRAM \\ JURNAL MAGISTER MANAJEMEN UNIVERSITAS MATARAM Maret 2018 \\ e- issn : 2548-3919}

Hipotesa pertama yang berbunyi: Semakin kuat Learning orientationsemakin kuat pularelational capabilityterdukung oleh data.Hal ini menunjukkan bahwa UMKM yang memilki orientasi kuat untuk belajar akan memiliki relational capability (RC) yang kuat. Hubungan bisnis bagi mereka adalah media untuk belajar dan proses membangun hubungan bisnis dipandang sebagai proses belajar. Komitmen dalam hubungan dengan pelanggan merupakan komitmen untuk belajar.Hubungan bisnis memberikan peluang untuk belajar tentang pelanggan, kebutuhan, selera dan persepsi mereka terkait tawaran perusahaan ataupun pesaing melalui shared vision internal perusahaan. Mempelajari dan memahami konsumen dan pesaing dapat ditingkatkan bilamana perusahaan memiliki keyakinan bahwa hubungan bisnis menjadi arena untuk belajar. Perusahaan dengan orientasi belajar memiliki ciri openmindyang kuat dan memperkuat kemampuannya untuk mengembangkan hubungan bisnisnya dengan pelanggan karena dari hubungan bisnis perusahaan dapat belajar dan memeperoleh pemahaman penting guna merumuskan strategi yang tepat untuk mempertahankan pelanggan dan mengalahkan pesaing. Hasil penelitian ini menegaskan bahwa UMKM memandang hubungan bisnis dengan pelanggan bukan hanya sebagai media penjualan tetapi lebih dari itu, yaitu arena untuk belajar.

Hasil penelitian ini tidak sejalan dengan hasil penelitian sebelumnya (Sulhaini dan Sulaimiah, 2017). Hasil penelitian mereka menunjukkan bahwa UMKM tidak menganggap hubungan bisnis sebagai arena untuk belajar dan iteraksi dengan pelanggan bukan sebagai mekanisme yang tersedia untuk belajar. Namun demikian penelitian ini sejalan penenlitian penelitian sebelumnya (Celuch et al., 2002; Jarrat, 2004;Santos-Vijande et al., 2005; Panayides 2007; Nykanen et al., 2009). Dengan demikian, dapat dikatakan UMKM di kota Mataram telah memahami peranan penting dari hubungan bisnis mereka dengan kosumen sebagai arena untuk belajar untuk data memahami selera konsumen, memahami perkembangan dan dinamika pasar.

Hipotesa ke dua berbunyi:Semakin kuat market orientation semakin tinggi pula relational capability. Hipotesa ini terdukung oleh data. Sejalan dengan hasil penelitianpenelitian sebelumnya (Smirnova dan Kushsh, 2006; Sulhaini dan Sulaimiah, 2017). Penelitian ini menegaskan bahwa UMKM dengan orientasi pasar yang kuat akan memacu kemampuannya untuk mengembangkan hubungan bisnis dengan pelanggan. Bilamana UMKM memiliki kemampuan relational yang kuat, memungkinkan mereka untuk mengembangkan strategi yang tepat guna memuaskan pelanggan. Orientasi pasar kuat mendorong UMKM untuk fokus kepada pelanggan dan pesaing, orientasi ini akan mestimulasi UMKM untuk menciptakan tawaran yang terbaik atau lebih baik dari pesaing. UMKM yang memiliki keinginan kuat untuk meningkat kinerja usahanya akan fokus pada pasarnya (konsumen/pelanggan dan pesaingnya) menekankan perhatiannya pada kemempuannya untuk mengembangkan hubungan bsnis dan memanfaatkannya untuk meningkatkan kinerja usaha. Mereka memandang komitmen dalam hubungan bisnis adalah sesungguhnya komitmen terhadap pelanggan.

Adapun hipotesa ke tiga berbunyi: Semakin kuat learning orientation semakin baik pula kinerja usaha tidak terdukung sepenuhnya oleh data. Bila dilihat dari arah hubungan antar variabel, hipotesa ini terdukung namun tidak signifikan karena $p>0.05$. Hasil ini menggambarkan bahwa tidak terdapat pengaruh langsung dari orientasi belajar terhadap kinerja usaha. Hasil ini tidak sejalan dengan hasil-hasil penelitian terdahulu (Baker dan Sinkula, 2000; Farrel, 2000). Perusahaan dengan orientasi belajar yang kuat akan mendorong karyawan belajar agar dapat memuaskan keinginan konsumen yang senantiasa dinamis. Orientasi belajar menstimulasi kreativitas agar dapat menciptakan produk yang tepat bagi pelanggan untuk memastikan keberhasil penjualan dan kinerja usaha yang 


\section{$J M M$ UNRAM \\ JURNAL MAGISTER MANAJEMEN UNIVERSITAS MATARAM Maret 2018 \\ e- issn : 2548-3919}

optimal. Akan tetapi penelitian ini menunjukkan bahwa komitmen untuk belajar, shared vision antar anggota organisasi usaha (kerjasama internal) serta kemampuan belajar sesuatu yang baru (openmindedness) belum dapat secara langsung menjamin kinerjausaha yang lebih tinggi.

Namun hasil penelitian ini menunjukkan bahwa orientasi belajar berpengaruh signifikan terhadap kinerja usaha melalui dampaknya terhadap kemampuan relasional $(0.117 \times 0,269=0,031)$ dengan tingkat signifikansi $(0,003 \times 0.012=0.0000)$. Orientasi ini dapat berdampak pada kinerja usaha apabila orientasi ini terimplementasi dalam upaya pengembangan kemampuan relational/RC.

Selanjutnya hipotesa ke empat yang berbunyi: Semakin kuat market orientation semakin baik kinerja usaha terdukung oleh data. Hasil ini sejalan dengan temuan penelitian-penelitian terdahulu (Kohli and Jaworski, 1990; Sanzo et al., 2003; Nasution dan Mavondo, 2008; Gonzales-Benito et al., 2009). Dengan orientasi pasar kuat, UMKM mampu menciptakan nilai pelanggan yang optimal sehingga dapat mencapai kinerja usaha yang lebih baik. Orientasi ini menjamin kemampuan UMKM untuk menciptakan kepuasan sosial maupun ekonomi melalui penguatan saling percaya dan komitmen bersama. Salah satu dimensi dari orientasi ini adalah orientasi kepada pelanggan, ini membantu UMKM untuk memahami pelanggan, keinginan dan kebutuhan mereka saat ini maupun kecenderungan-kecenderungan di masa yang akan datang. UMKM dapat menciptakan tawaran-tawaran yang selalu menarik bagi pelanggannya karena didasarai oleh pemahaman yang baik terhadap pelanggan. Orientasi ini tidak hanya mampu mendekatkan UMKM dengan pelanggannya tetapi juga memahami strategi pesaing sehingga mampu merumuskan strategi bersaing dan memenangkan persaingan. Hal ini tentunya berdampak pada peningkatan market share dan kinerja usaha. Dengan demikian dapat dikatakan bahwa orientasi ini mampu meningkatkan daya inovasi dan kreatifitas dalam penciptaan nilai pelanggan melalui pengembangan produk maupun proses pemasarannya.

Hipotesa terakhir yang berbunyi Semakin kuat relational capability semakin baik pula kinerja usaha terdukung oleh data. Hasil ini mempertegas apa yang telah dikemukakan oleh Ngugi et al. (2010). Kapabilitas relasional dapat menghantarkan UMKM untuk memetik banyak manfaat dari hubungan bisnisnya. Salah satu dari manfaat itu adalah jaminan atas kesuksesan penjualan produk. Melalui hubungan bisnis yang kuat, UMKM dapat mengetahui dengan baik kebutuhan dan keiginan pelanggan. Ide-ide pengembangan produk baru dapat muncul dari pelanggan sehingga inovasi produk tidak ada yang sia-sia atau sudah terjamin kesuksesan penjualannya. Ide-ide penting dapat diperoleh bilamana hubungan bisnis ditandai oleh adanya saling percaya, memuaskan secara sosial dan ekonomi serta komitmen bersama yang kuat. Tidak hanya itu, kapailitas ini membantu UMKM mengidentifikasi kebutuhan laten pelanggan kemudian mengembangkan sistem internal organisasi perusahaan untuk mendukung pengembangan produk baru dari tahap awal hingga pemasarannya sehingga kesuksesan pengembangan produk baru dapat diprediksi lebih besar. Hal ini menunjukkan bahwa kinerja usaha/pemasaran sangat ditentukan oleh kemampuan membangun hubungan bisnis dengan pelanggan (Broring dan Cloutier, 2008). Dengan demikian, kapabilitas relasional menjadi penentu kinerja usaha. Hubungan bisnis yang dibangun berdasarkan mutual trust and mutual commitment akan memperpendek waktu dan mengurangi resiko dalam menciptakan dan mengembangkan produk serta memudahkan pemasarannya. Sehingga hubungan bisnis yang kuat dengan pelanggan memperbesar peluang kesuksesan pemasaran produk baru dan daya saing perusahaan. 


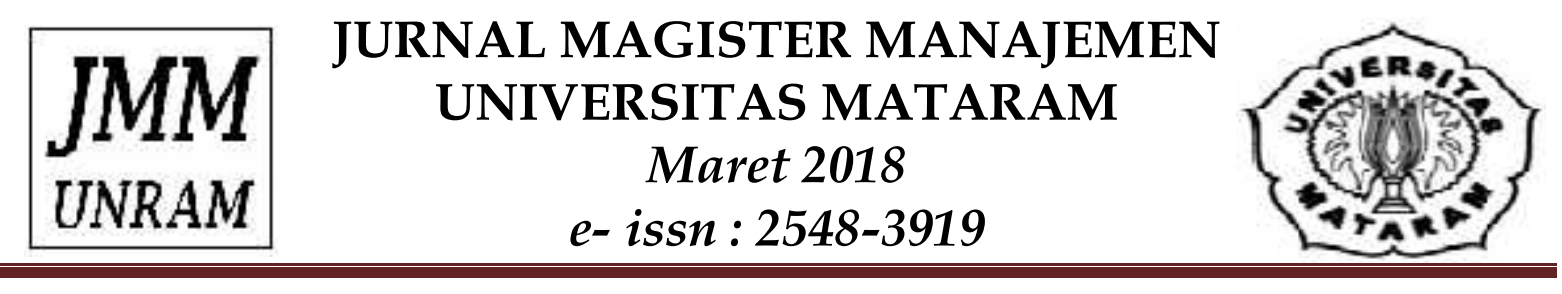

\section{KESIMPULAN DAN SARAN}

Penelitian ini telah menguji pengaruh budaya organisasi (Learning dan Market orientations) terhadap kapabilitas relasional dan kinerja usaha. Penelitian ini memberikan konstribusi penting terhadap ilmu pengetahuan dan implikasi manajerial karena dilakukan di kalangan UMKM yang berada di kota kecil dan di negara berkembang. Hasil penelitian ini tidak hanya memberikan bukti empiris tetapi juga pemahaman penting untuk mengisi research gap yang ada.

Penelitian ini menunjukkan bahwa di kalangan UMKM, learning orientation dan market orientation sangat penting untuk mendorong pengembangan kapabilitas relasional dan kinerj usaha. Orientasi budaya tersebut meruakan fondasi bagi kemampuan perusahaan untuk ekspansi atau memperluas jaringan bisnisnya. Learning orientation mendorong UMKM menggunakan hubungan bisnisnya untuk belajar. Kesempatan belajar adalah merupakan hal penting untuk dapat mendorong UMKM belajar tentang konsumen, memahami kebutuhan, keinginan dan perilaku konsumen bahkan pesaing. Ini menggambarkan bahwa melalui interaksi dengan konsumen dalam kerangka hubungan bisnis memungkinkan UMKM untuk belajar sekaligus berorientasu kepada konsumen dan pesaing. UMKM yang berorientasi kuat terhadap pasar dan belajar (MO \& LO) akan menganggap bahwa hubungan bisnis sangat penting dan akan berusaha untuk membangun kapabilitas relasional. Pada akhirnya, kinerja usaha terjamin.

Hasil menarik yang dapat diperoleh dari penelitian ini, bahwa LO UMKM tidak dapat secara langsung menjamin tercapainya kinerja usaha yang tinggi, namun harus melalui proses pengembangan kapabilitas relasional. Dengan demikian, LO tidak dapat dengan sendirinya ditumbuhkan dalam perusahaan tetapi harus diiringi oleh komitmen untuk membangun kapabilitas tersebut. Adapun saran yang dapat diajukan sesuai dengan hasil penelitian dapat dilihat sebagai berikut:

Budaya organisasi (LO dan MO) harus dikembangkan dan ditanamkan dalam perusahaan skala mikro, kecil dan menengah yang dapat menumbuhkan kapabilitas relational. Sehingga, pembinaan UMKM melalui pelatihan dan pendampingan harus menekankan pada pengembangan budaya organisasi tersebut. Penekanan pada pentingnya belajar dan memahami pasar secara terus menerus melalui hubungan bisnis dengan konsumen. Interaksi (baik dalam proses penjualan maupun negoisasi dan respon terhadap keluhan) dengan konsumen harus dipandang sebagai proses belajar untuk memahami konsumen. Kapabilitas relasional dibangun untuk memastikan implementasi budaya organisasi berujung kepada kinerja usaha yang lebih baik.

Bagi penelitian selanjutnya perlu melihat budaya organisasi yang lain seperti entrepreneurial orientation (EO) dan strategi-strategi manajerial dan dampaknya terhadap kapabilitas relasional. Hal ini diharapkan dapat memperluas pemahaman terkait kapabilitas tersebut. Penelitian in telah berhasil mengisi research gap terkait pengaruh budaya organisasi terhadap kapabilitas relasional, namun masih perlu penelitian lebih lanjut terkait budaya masyarakat dan dampaknya terhadap budaya organissi dan kapabilitas relasional. 


\section{JURNAL MAGISTER MANAJEMEN UNIVERSITAS MATARAM Maret 2018

\section{DAFTAR PUSTAKA}

Baker, W.E., and Sinkula, J.M., 1999, Learning Orientation, Market Orientation and Innovation: Integrating and Extending Models of Organisational Performance, Journal of Market Focused Management, Vol. 4, Pp. 295-308.

BrÖring, S. and Cloutier, L.M. 2008. Value Creation in New Product Development within Converging Value Chains, the Food Journal. Vol. 110. No.1., pp. 76-97.

Gonzales-Benito, O.Gonzales-Benito, J.G., and Gallego, P.A.M, 2009, The role of Entrepreneurship and market orientation in Firms success, European Journal of Marketing, vol. 43, no $3 / 4$, pp. 500-522.

Celuch, K.G., Kasouf, C.J., and Peruvemba, V., 2002, The Effect of Perceived Market and Learning Orientation on Assessed Organisational Capabilities, Industrial marketing Management, Vol. 31, Pp.545-554.

Day, G.S., 2003, Creating a Superior Customer-Relating Capability, Marketing Science Institute, Fall,

Farrell, M. A., 2000, Developing a Market-Oriented Learning Organisation, AustralianJournal of Management, Vol. 25, No. 2, Pp. 201- 222.

Ferdinand, A., 2014. Structural Equation Modeling, Ed. 5. BP UNDIP-UNDIP Press, ISBN: 979-9156-75-0.

Foley, A. and Fahy, J., 2004, Towards a Further Understanding of the Development of Market Orientation in the Firm: A Conceptual Framework Based on The Market-Sensing Capability, Journal of Strategic Marketing, Vol. 12, pp. 219-230.

Gima, K.A, 2002, The Social Capital of the Top Marketing Team, Inter-firm Market Learning Capability, and Business Performance: A Test of a Mediating Model, Marketing Science Institute, $02-118$

Hair, J.F., Black, W.C, Babin, B.J., Anderson, R.E., and Tatham, R.L. (2006).Multivariate Data Analysis. New Jersey: Pearson Education International.

Hakala, H., Kohtamaki, M., 2011, Configuration of Entrepreneurial customer and technology orientation, International Journal of Entrepreneurial Behaviour and Research, Vol. 17 No.1, pp. 64-81.

Iglesias, O., Sauquet, A. and Montana, J., 2011, The Role of Corporate Culture in Relationship Marketing, Vol. 45 No. 4, pp. 631-650.

Jarratt, D.G., 2004, Conceptualising a relationship management capability, Marketing Theory, vol. 4, pp. 287-309.

Jones, E., Chonko, L.B., and Roberts, J.A., 2003, Creating a partnership-oriented, knowledge creation culture in strategic sales alliances: a conceptual framework, Vol. 18, No. 4/5, Pp. 336-352.

Kohli, A. K. and Jaworski, B.J. (1990). Market Orientation: The Construct, Research Propositions, and Managerial Implications. The Journal of Marketing, 54(2),1-18.

Kropp, F. Lindsay N.J., and Shoham, A., 2006, Entrepreneurial, market and learning orientations and international entrepreneurial business venture performance in South African Firms, International Marketing Review, Vol. 23 No.5, pp. 504-523.

Kucukkancabas, S., Akyol, A., and Ataman, B.M., 2009, Examination of the Effects of the Relationship Marketing Orientation on the Company Performance, Qual Quant, Vol. 43, Pp. 441-450.

Lin, CH., Peng, C., and Kao, D.T., 2008, The Innovatinevess effect of Market Orientation and Learning Orientation on Business Performance, International Journal of Manpower, Vol. 29 No.8, 2008, pp. 752-772. 
Matthing, J., Sanden, B., and Edvardson, B., 2004, New Service Development: Learn from and with Customers, Industrial Journal of Service Industry Management, Vol. 15, no.5, pp. 479-498.

McGuiness, T., and Morgan, R.E. 2006. The effect of Market and Learning Orientation on strategy dynamics, European Journal of Marketing, vol. 39. No 11/12, pp. 1306-1326.

Nasution, H.N. and Mavondo, F.T., 2008. Organisational Capabiliities: Antecedents and Implications for customer value, European Journal of Marketing, vol. 42 no. 3/4 pp. 477501.

Ngugi, I.K, Johnsen, R.E, Erdelyi, P., 2010, Relational capabilities for value co-creation and innovation in SMEs, Journal of small Business and Enterprise Development, vol. 17, no. 2, pp. 260-278.

Nykanen et al, 2009, Towards a more social perspective of network management: an action research study on trust and commitment, $25^{\text {th }}$ IMP conference proceeding, Marsile, France.

Panayides, P.M., 2007, The Impact of Organisastional Learning on Relationship Orientation, logistics service effectiveness and performance, Industrial Marketing Management,

Pentina, I. And Strutton, D., 2007. Information Processing and new product success: a meta-analysis, European Journal of Innovation Management, vol. 10, no. 2, pp. 149-175.

Rodriguez-Diaz, M., and Espino-Rodriguez, T.F., 2006, Redesigning the supply chain: reengineering, outsourcing and relational capabilities, Business Process Management, Vol. 12, no. 4, pp. 483-502.

Santos-Vijande, M. Perez, M.J.S., Gonzales, L.I.A., and Casielles, R.V., 2005, Organisational Learning and Market Orientation: Interface and Effects on Performance, Industrial Marketing Management, Vol.34, Pp. 187-202.

Sanzo, M.J., Santos, L.M., Vazquez, R. and Alvares, L.I., 2003, The Role of Market Orientation in Business Dyadic Relationships: Testing an Integrator Model, Journal of Marketing Management, Vol. 19, Pp. 73-107.

Sivadas, E., and Dwyer, F.R., 2000, An Examination of Organisational Factros Influencing New Product Success in Internal and Alliance-Based Processes, Journal of Marketing, Vol. 64 pp-31-49.

Smirnova, M., and Kushch, S., 2009, Understanding the Role of Relational Capabilities in Buyer-Seller Relationships, The paper was published at the 22nd IMP-conference in Milan, Italy in 2006.

Smirnova, M., Naude, P., Mouzas, S., Kushch, S.P, 2009,Market Orientation Driving Relational Capabilities Development? The Case of Russian Industrial Firms, Proceeding of 25th IMP Conference

Sulhaini, 2012, Understanding Business Relationship Development in the Context of a High-Risk and Uncertain Country Market, Fortcoming, Edisi April, Journal Ventura, terakreditasi, Edisi April.

Sulhaini dan Sulaimiah, 2017, Assessing Value Co-creation and New Product Success from Cultural Orientations and Relationship marketing Perspectives, Journal of relationship Marketing, no 16, no 1, pp. 21-39.

Tan, Y.C., Mavondo, F., and Worthington, S., 2011. Organisational Capabilities and Relationship Quality, Performance implications for Palm Oil Processors in Malaysia, AsiaPacific Journal of Marketing, 23 (2), 152-164. 


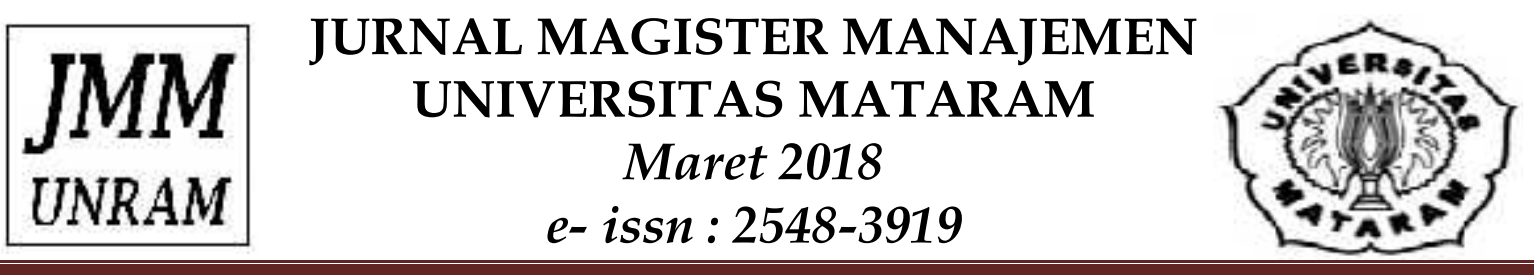

Voss, K., Johnson, J.L. Cullen J.B., Sakano, T., and Takenouchi, H., 2006, Relational exchange in US-Japanese marketing Strategic alliances, International Marketing Review, Vol. 23, No 6, pp. 610-635.

Wang, E. T.G. and Wei, Hsiao-Lan, 2005, The Importance of Market Orientation, Learning Orientation and Quality Orientation Capability in TQM: An Example from Taiwanese Software Industry, Total Quality Management, Vol. 16, No. 10, pp. 1161 - 1177. 